\title{
Clinico-epidemiological profile of congenital heart disease in a tertiary care center - a retrospective descriptive study
}

\author{
Ramawat P. ${ }^{1}$, Jain N. ${ }^{2 *}$
}

DOI: https://doi.org/10.17511/ijpr.2020.i07.02

\footnotetext{
1 Pramila Ramawat, Assistant Professor, Department of Pediatrics, MGM Medical College, Indore, Madhya Pradesh, India.

2* Nilesh Jain, Associate Professor, Department of Pediatrics, MGM Medical College, Indore, Madhya Pradesh, India.
}

\begin{abstract}
Aims and objective: To study the clinical-epidemiological profile of congenital heart disease in hospitalized children. Material and methods: A retrospective study was planned in a tertiary care center in Central India. Children between ages 1 month to 14 years with CHD were included in this study. Type of CHD, clinical presentation, anthropometry, demographic profile, and the outcome was recorded. Result: A total of 65 patients were included in the study. 43 patients were suffering from acyanotic CHD and 22 were having cyanotic CHD. Most of the children admitted were below 1 year of age $(n-67 \%)$. Males (42) were more reported in the present study than females (23). Conclusion: CHDs are one of the commonest birth defects, timely diagnosis and intervention are very important to decrease mortality and morbidity in pediatric patients.
\end{abstract}

Keywords: CHD, Birth defect, Epidemiological

Corresponding Author

Nilesh Jain, Associate Professor, Department of Pediatrics, MGM Medical College, Indore, Madhya Pradesh, India.

Email: nileshkalashdhar@gmail.com
How to Cite this Article

To Browse

Ramawat $\mathrm{P}$, Jain N. Clinico-epidemiological profile of congenital heart disease in a tertiary care center - a retrospective descriptive study. Pediatric Rev Int J Pediatr Res. 2020;7(7):326-330.

Available From

https://pediatrics.medresearch.in/index.php/ijpr/arti cle/view/620

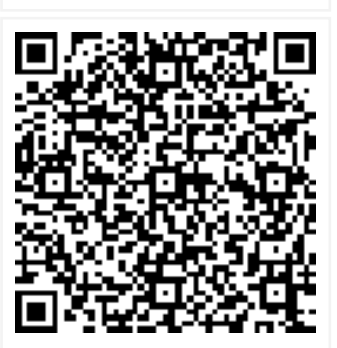

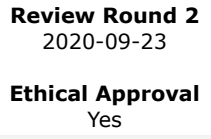

Review Round 3 


\section{Introduction}

Congenital heart diseases are the most common malformations or defects in babies responsible for $28 \%$ of cases of congenital birth defects [1]. In India prevalence of $\mathrm{CHD}$ at birth is $9 / 1000$ live birth so an estimated 2,40,000 children born with congenital heart defects every year in our country [2]. Most of the time it missed in the newborn period due to late clinical presentation with the change in cardiovascular physiology especially pressure changes in heart chambers and major arteries.

Many times its presentation is delayed or diagnosed incidentally when the child came for other health issues. It may be diagnosed from infancy to adolescence and sometimes in adulthood depending on the type of $\mathrm{CHD}$ and its presentation as well as the knowledge, care, and concern of caregivers. Untreated CHD in most cases associated with a high rate of morbidity and mortality, responsible for a large impact on families, societies, and a big challenge for health care providers.

Early diagnosis and timely intervention can improve outcomes in the form of a healthy child with improved life expectancy and decreased numbers of hospital visits. It is possible because of improved management of $\mathrm{CHD}$ in the last decades, its availability, and government support through various health schemes.

Timely detection and confirmation of CHD by $\mathrm{ECHO}$ is necessary to save these children because it affects their growth and responsible for multiple hospital admission due to recurrent respiratory infections, CHF, or cyanotic spells.

In our country due to lack of awareness and late presentation many times CHD missed in the early period result in increased incidences of morbidity and mortality in the later period. The current study was planned to understand the clinicalepidemiological pattern of CHD in our area which can help us to improve the quality care of these children.

\section{Material and Methods}

It is a hospital-based study in a tertiary care center of central India.

The study duration was 5 months from October 2019 to February 2020. The present study is a retrospective descriptive study.
Children admitted to the pediatric department with CHD (already diagnosed or diagnosed during hospital stay) during this period were included in the study.

\section{Inclusion criteria}

Age 1 month to 14 years

With CHD confirmed by ECHO

\section{Exclusion criteria}

Age $<1$ month

The unstable patient expired before ECHO

Patient with acquired heart disease

Readmission of the already enrolled patient

Data were collected from the hospital's record section and assessed for the type of CHD - cyanotic or acyanotic, single defect, or complex $\mathrm{CHD}$ and associated comorbidities.

The present study collected data about the clinical presentation, age, cause of hospitalization (CHF, respiratory infections, cyanotic spell, etc.), the outcome - discharge, death, duration of hospital stay, complications, anthropometry, and demographic profile.

Statistical analysis done by SPSS 16 software, ratio, percentage, and mean were calculated.

\section{Result}

A total of 65 patients included in the present study among them majority were boys. $67.6 \%$ of children were below 1 year of age, $20 \%$ were between 1 to 5 years of age, $12 \%$ of children diagnosed the first time were above 5 years of age. $66 \%$ of children were suffering from acyanotic CHD while $33.8 \%$ of patients admitted with cyanotic CHD.

$47.7 \%$ of children presented with a single defect and53.3\% of patients had congenital heart defects more than one, $50.7 \%$ of patients were already diagnosed and $49.2 \%$ diagnosed the first time. $63 \%$ of patients were discharged, 20\% LAMA, and 15\% deaths, 1 patient refer to the higher center where cardiothoracic surgery facility available for complex CHD.

VSD was diagnosed in $44.6 \%(n-29)$ patients as most common CHD - isolated defect in $20 \%(n-13)$ and associated with other defects in $24.6 \%(n-16)$ patient followed by ASD in $17 \%(n-11)$, PDA in $6 \%$ 
$(\mathrm{N}-4)$, TOF in $12 \%(n-8)$ and TGA in $7.6 \%(n-5)$ patients.

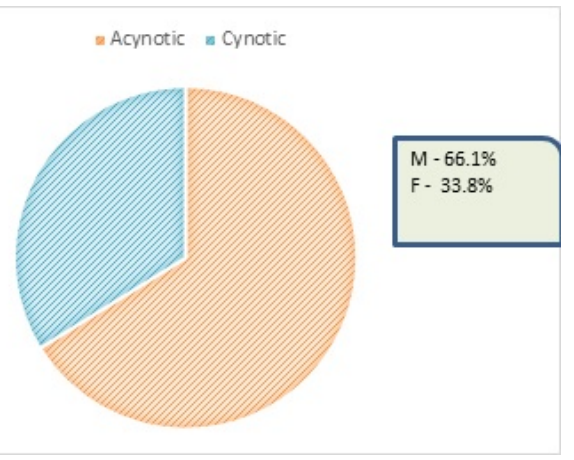

Fig-1: Distribution of CHD according to gender.

Other defects were TAPVC IN 3, Coarctation of Aorta in 2, Hypoplastic right ventricle in 1, AV canal defect in 1 , Ebste in anomaly 1 , bicuspid aortic valve $1, P S$ in 1, TGA in 5, TR in 2, Tricuspid atresia in 1 ,AS in 1 child. Pulmonary hypertension were reported in $7.6 \%(n-5)$ and Essenmengerisation develop in 1 patient.

\section{Table-1: Type of CHD}

\begin{tabular}{|l|l|}
\hline \multicolumn{1}{|c|}{ Type of CHD } & \multicolumn{1}{c|}{ No. of patients(In percentages) } \\
\hline VSD & $29(44.6 \%)$ \\
\hline ASD & $11(17 \%)$ \\
\hline PDA & $4(6 \%)$ \\
\hline TOF & $8(12 \%)$ \\
\hline TAPVC & $3(4.6 \%)$ \\
\hline TGA & $5(7.6 \%)$ \\
\hline PS & $1(1.5 \%)$ \\
\hline Ebstein's anomaly & $2(3 \%)$ \\
\hline Coarctation of aorta & $3(4.6 \%)$ \\
\hline Others & $6(9.2 \%)$ \\
\hline Complex CHD & $6(9.2 \%)$ \\
\hline
\end{tabular}

The most common reason for hospitalization was a respiratory infection in 30 patients, 10 patients admitted with $\mathrm{CHF}$, and 11 patients with the cyanotic spell. Other less common causes of admission were brain abscess - 1, a thalamic abscess - 1, reflex seizure - 1, and right foot gangrene -1 . Among other reasons for admission were FTT in 7 patients, severe anemia in 5 patients.

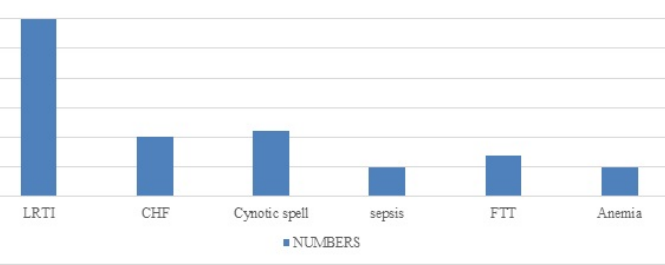

\section{Fig-2: Reasons for hospitalization in CHD patient}

Other associated co morbidity-4 patients were syndromic (3 with Down's syndrome, 1 with Turner syndrome), anorectal malformation ( $n-1)$, chronic kidney disease $(n-1)$.

\section{Discussion}

The reported prevalence of $\mathrm{CHD}$ in the normal population worldwide is range from 1.01 to 17.5 per 1000 live birth $[3,4]$ In the present study prevalence of $\mathrm{CHD}$ in the hospitalized patient were $1.05 \%$. In other studies incidence of CHDs in hospitalized children was $8.6 \%$ by Mohamad et al [5], 5.8\% by Shah et al [6]. In the present study boys ( 1.7 times) are in majority than girls, it was also presented in many other studies $[7,8]$. The reason for male predominance in studies may be caregivers are more concerned about boy's health than girls, so they received timely hospitalization and management.

In the present study children diagnosed before 1 year of age were $67 \%, 20 \%$ between 1 to 5 years of age, and $12 \%$ after 5 years of age. Another study suggested the same results [8,9]. According to Jatav et al. $37.06 \%$ of CHD cases were detected by the age of 1 year and up to $15.51 \%$ were detected after the age of 18 years [9]. Shah et al found that $9.1 \%$ presented before 1 month of age, $46.4 \%$ presented between 1 to 12 months of age [6].

According to Karthinga et al $31 \%$ of infants with CHD diagnosed before 1 year of age. In this study, it was found that $32 \%$ of children were diagnosed beyond infancy. In our opinion, many times diagnosis delayed may be due to $\mathrm{CHD}$ is asymptomatic, caregiver's lack of awareness, or a neglected child [10].

In the present study associated comorbidities were Down syndrome (n-3), Turner syndrome (n-1) CKD $(n-1)$ Anorectal malformation (n-1), hepatoblastoma (n-1), and global development delay $(n-1)$. In the study by Sandeep et al. the most common associated anomaly was involving the musculoskeletal system (58.33\%) which includes CTEV, polydactyly, and webbed neck. Down syndrome was seen in 5 children. A study by Karthinga et al. reported cleft lip and palate (n-2), Down syndrome (n-1), and imperforate anus, inguinal hernia, and biliary atresia were found in 2 patients each [10]. 
Acyanotc CHD was present in $66 \%$ of cases, in $47 \%$ of cases single defect present. VSD was a most common defect $(44 \%)$ in the present study and as a single defect presented in $24 \%$ of children, similar results were reported in other studies eg. Kasturi et al $-27 \%$ [11], Manon $Y$ et al $-52.5 \%$ [12], Jatav et al $28.4 \%$ [9]. The second most common defect was ASD (16.9\%).

Other common defects were PDA (6.1\%), TOF (12.3\%), TAPVC (4.6\%), PS (7.6), TGA (7.6\%). Complex CHDs were presented in $9.2 \%$ of patients. Pulmonary arterial hypertension developed in $7.5 \%$ of patients. Essenmengerisation was present in 1 patient. Acynotic CHDs are more common than cyanotic CHDs in the present study as reported in the literature.

The most common cyanotic CHD was TOF. The most common cause for hospitalization was an acute respiratory infection in acynotic CHDs while the cyanotic spell was a common cause for hospitalization in cyanotic CHD similar results were reported in other studies $[13,14]$.

The most common reason for hospitalization was acute respiratory infection $38.4 \%$, followed by CHF $12.3 \%$ and cyanotic spell $16.9 \%$, sepsis was also common presentation 2 children presented with shock, CNS complications were presented in 3 patients- 1 with brain abscess, 1 with thalamic abscess and 1 with reflex seizure.

Severe anemia was found in 5 patients and 5 patients admitted due to not gaining weight. Sharmin et al reported most common presentation was breathlessness $(60 \%)$ followed by fatigue $(54 \%)$, cough $(43.7 \%)$, poor weight gain $(41.7)$, recurrent respiratory infection $(34.8 \%)$, fever $(28.7 \%)$, cyanotic spell $(13 \%)$ and seizures $(1.7 \%)$ [13].

Karthinga et al reported that patients admitted with fever $(78.7 \%)$, breathlessness $(72.7 \%)$, feeding problems $(18 \%)$, cyanosis $(18 \%)$, poor weight gain $(12 \%)$, and others $(21 \%)$ [10]. Sandeep et al also reported breathlessness was the most common clinical presentation in cyanotic and acynotic heart diseases followed by respiratory tract infection and failure to thrive.

Respiratory distress and fever were the most common causes in studies for admission; other common problems were cyanotic spell and poor weight gain $[13,14]$.
Limitations of the present study were small sample size and only hospitalized children included in the study which may be the only iceberg of disease because our setup is a tertiary care center, not very helpful in assessing the true prevalence of CHDs in the community. Newborn screening by bedside ECHO may help to assess true incidences in society and for timely interventions.

\section{Conclusion}

Congenital heart disease is the 3rd commonest birth defect. Timely appropriate management is very important in these children to improve survival and decreased hospitalization need.

\section{What does the study add to the existing knowledge}

It was found that CHD is a very common congenital defect in children and missed many times in newborns and early infancy result in an increased risk of morbidity and mortality due to various complications. Community and hospital-based screening programs in which newborns screened for the presence of CHD may be useful for early diagnosis and timely management.

\section{Author's contribution}

Dr. Pramila Ramawat: Concept, study design

Dr. Nilesh Jain: Data analysis, manuscript preparation

\section{Reference}

01. Dolk H, Loane. EUROCAT Steering Committee. Congenital Heart Defect in Europe- 2000-2005. Newtownabbey, Northern Ireland- University of Ulster.

March 2009. Available from: Accessed May 18, 2017 [Article] [Crossref]

02. Saxena A. Congenital heart disease in India- $A$ status report. Indian J Pediatr. 2005;72;595-8.

doi: $\quad 10.1007 / \mathrm{s} 13312-018-1445-7 \quad$ [Crossref]

03. Brassili A, Mokhtar SA, Dabous NI, Zaher SR, Mokhtar MM, Zaki A. Congenital heart disease among school children in Alexandria, Egypt- an overview on prevalence and relative frequencies. J Trop Pediatr. 2000;46(6)357-362. doi: $10.1093 /$ tropej/46.6.357 [Crossref] 
04. Kapoor R, Gupta S. Prevalence of Congenital Heart Disease, Kanpur, India. Indian Pediat. 2008;45(4)309-311.

[Crossref]

05. Al-Hamash MS. Pattern of Congenital Heart Disease- a Hospital-Based Study. Al-Kindy Col Med J. 2006;3(1)44-48.

[Crossref]

06. Shah GS, Singh MK, Pandey TR, Kalakheti BK, Bhandari GP. Incidence of congenital heart disease in tertiary care hospital. Kathmandu Univ Med J. 2008;6(1)33-36.

[Crossref]

07. Begam R, Pathak K, Das $H$. Incidence and pattern of congenital heart disease in children $a$ hospital-based study. IOSR J Dent Med Sci. 2016;15(6)8-11.

[Crossref]

08. Borzouee M, Jannati $M$. Distribution and Characteristics of the heart disease in Pediatric Age Group in Southern Iran. Iran Cardiovasc Res J. 2008;2(1)48-51.

[Crossref]

09. Jatav RK, Kumbhare MB, Srinivas M, Rao DR, P Goutham Kumar, Reddy PR, et al. Prevalence and pattern of congenital heart diseases in Karimnagar, Andhra Pradesh, India, diagnosed clinically and by trans-thoracic-twodimensional echocardiography. Int J Res Med Sci. 2014;2(1)186-192.

doi: $10.5455 / 2320-6012 . i j r m s 20140236$ [Crossref]
10. Karthiga S, Pathak S, Lazarus M. Clinical and Anthropometric Profile of Congenital Heart Disease in Children Admitted in Pediatric Ward. Int J Sci Stud. 2017;5(5)112-117.

doi: $10.17354 /$ ijss/2017/405 [Crossref]

11. Kasturi L, Kulkarni AV, Amin A, Mahashankar VA. Congenital heart disease: clinical spectrum. Indian Pediatr. 1999;36(9)953.

[Crossref]

12. Yasmeen $M$, Rehana $M$, Feroz $M$. Pattern of congenital heart disease at Liaquat University Hospital, Hyderabad. Pakistan Heart J. 2007;40;1(2).

[Crossref]

13. Sharmin L, Haque M, Bari M, Ali M. Pattern and Clinical Profile of Congenital Heart Disease in $A$ Teaching Hospital. J Teachers Assoc. 2008;21(1)58-62.

doi: $10.3329 /$ taj.v21i1.3221 [Crossref]

14. Sandeep VH, Laxmi NI, Venkatesh P, Vijayanath V. Clinical study of congenital heart disease in infants. J Pharm Sci Innov. 2013;2;15-18. [Crossref] 